\title{
DAYA DUKUNG BUDIDAYA IKAN KERAPU PADA KERAMBA JARING APUNG TELUK AWANG DAN TELUK BUMBANG, NTB
}

\section{CARRYING CAPACITY OF GROUPER CULTIVATION ON FLOATING NET IN AWANG BAY AND BUMBANG BAY, NTB}

\author{
Lydia S Marpaung ${ }^{1}$, Yusli Wardiatno ${ }^{1}$, Isdradjad Setyobudiandi ${ }^{1}$, Taslim Arifin ${ }^{2}$ \\ ${ }^{1}$ Departemen Manajemen Sumberdaya Perairan, \\ Fakultas Perikanan dan Ilmu Kelautan, Institut Pertanian Bogor \\ ${ }^{2}$ Pusat Penelitian dan Pengembangan Sumberdaya Laut dan Pesisir, \\ Balitbang KP-KKP Jakarta
}

Korespondensi: lydiamarpaung26@gmail.com, ywardiatno@hotmail.com, isdradjad@gmail.com, a_taslimar@yahoo. com

\begin{abstract}
The carrying capacity is potential of the waters fot utilize coastal or ecosystem resources without cousing damage dan sustainable. This study aims to determine carrying capacity of the water for accommodate the waste from grouper cultivation activities in floating net in Awang Bay and Bumbang Bay. This research was conducted from April until novemver 2015. The research method used is survey method with direct measurements in Awang Bay and Bumbang Bay waters. Carrying capacity analysis used to estimated loading waste the waters from antropogenic and from grouper cultivation activities. The calculation result carrying capacity in Awang Bay and Bumbang Bay waters from $\mathrm{N}$ antropogenic waste are 39,14 kg/day, $\mathrm{NH}_{3}$ average concentration is $0,0081 \mathrm{mg} / \mathrm{l}$ in Awang Bay and 0,0062 mg/l in Bumbang Bay. The estimated of floating net can be used in Awang Bay are 67 units and 248 units of floating net can be used in Bumbang Bay.
\end{abstract}

Keyword: Awang Bay, Bumbang Bay, carrying capacity, floating net

\begin{abstract}
ABSTRAK
Daya dukung perairan merupakan potensi perairan untuk memanfaatkan sumber daya pesisir atau ekosistem tanpa menimbulkan kerusakan dan dimanfaatkan secara berkelanjutan. Penelitian ini bertujuan untuk mengetahui daya dukung perairan menampung limbah yang masuk dari kegiatan budidaya ikan kerapu pada keramba jaring apung perairan Teluk Awang dan Teluk Bumbang. Penelitian ini dilaksanakan pada Bulan April sampai November 2015. Metode yang digunakan dalam penelitian ini adalah survey dengan pengukuran langsung di perairan Teluk Awang dan Teluk Bumbang. Analisis daya dukung digunakan untuk mengestimasi beban limbah yang masuk ke perairan baik dari antropogenik maupun dari kegiatan budidaya ikan dalam keramba jaring apung. Hasil perhitungan estimasi daya dukung perairan Teluk Awang dan Teluk Bumbang berdasarkan total limbah N antropogenik sebesar 39,14 kg/hari dengan konsentrasi rata-rata $\mathrm{NH}_{3}$ sebesar $0,0081 \mathrm{mg} / 1$ pada Teluk Awang dan 0,0062 mg/l pada Teluk Bumbang. Estimasi jumlah unit keramba jaring yang dapat digunakan di Teluk Awang sebanyak 67 unit dan 248 unit keramba jaring apung yang dapat digunakan di Teluk Bumbang.
\end{abstract}

Kata kunci: daya dukung, keramba jaring apung, Teluk Awang, Teluk Bumbang 


\section{PENDAHULUAN}

Pengembangan marikultur atau perikanan budidaya di suatu perairan didasarkan kepada potensi perairan itu sendiri. Teluk sebagai perairan semi tertutup dan terletak di wilayah pesisir sangat potensial dikembangkan kegiatan marikultur. Kondisi perairan mempengaruhi kapasitas perairan dalam menangkap limbah yang masuk, baik limbah yang berasal dari budidaya maupun limbah yang berasal dari kegiatan antropogenik. Prospek kegiatan budidaya laut yang sangat menjanjikan dalam meningkatkan perekonomian masyarakat pesisir, keberlanjutan kegiatan ini akan sangat tergantung pada kemampuan lingkungan atau tergantung pada daya dukung lingkungan perairan tersebut. Agar kegiatan budidaya tersebut berlangsung secara berkelanjutan, maka pengembangan perlu disesuaikan dengan karakteristik perairan. Maka diperlukan data dan informasi yang terintegrasi, aktual dan akurat untuk menentukan daya dukung agar kondisi perairan dapat terjaga dan berkelanjutan (Sachoemar 2006). Salah satu hal yang perlu diperhatikan dalam pengembangan budidaya laut adalah adanya perubahan parameter lingkungan, karena dapat mempengaruhi luasan dan area lokasi budidaya (Anggoro 2004).

Secara administrasi Teluk Awang dan Teluk Bumbang merupakan bagian Desa Mertak Kabupaten Lombok Tengah,di mana Teluk Awang berada pada posisi $116^{\circ} 23^{\prime} 41,46^{\prime \prime}$ Bujur Timur dan 8 $8^{\circ} 1^{\prime} 52,10$ " Lintang Selatan, Teluk Bumbang berada pada posisi $116^{\circ} 21^{\prime} 36,78^{\prime \prime}$ Bujur Timur dan 854'59,68" Lintang Selatan. Luasan perairan Teluk Awang 258,33 ha (Ramdhan et al. 2014) sedangkan luas perairan Teluk Bumbang 940 ha (Tarunamulia et al. 2015) serta memiliki sumber daya perikanan budidaya yang melimpah. Tujuan dari penelitian ini untuk mengetahui daya dukung perairan menampung limbah yang masuk dari kegiatan antropogenik dan budidaya ikan kerapu dalam keramba jaring apung perairan Teluk Awang dan Teluk Bumbang.

\section{METODE PENELITIAN}

\section{Lokasi dan Waktu Penelitian}

Penelitian ini dilaksanakan di perairan Teluk Awang dan Teluk Bumbang pada bulan April sampai November 2015. Lokasi pengambilan sampel air diambil mewakili semua kondisi perairan yang terdapat di lokasi penelitian. Metode yang digunakan adalah metode survey dengan melakukan pengukuran langsung di lokasi penelitian (Gambar 1).

\section{Jenis dan Sumber Data}

Penelitian ini menggunakan data primer dan data sekunder. Pengumpulan data primer dilakukan dengan pengamatan dan pengukuran langsung di lapangan. Data primer yang diamati dan diukur seperti kondisi kualitas perairan yang meliputi parameter fisika dan kimia. Data sekunder meliputi data studi literatur dan data dari instansi terkait (Tabel 1).

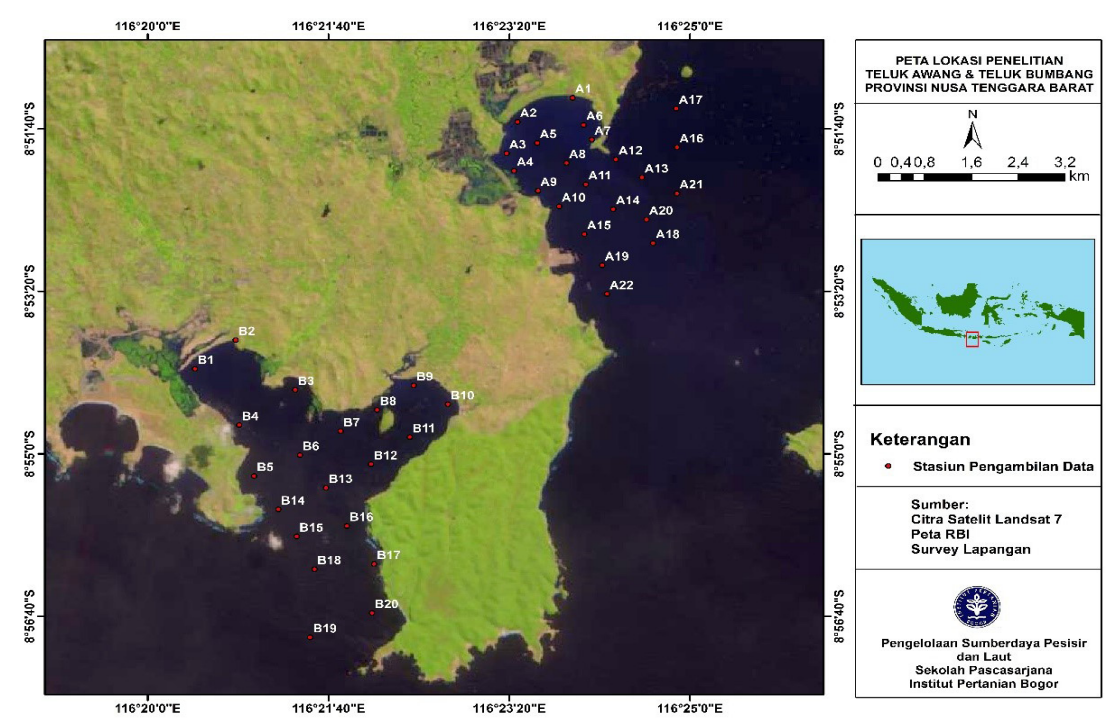

Gambar 1 Peta lokasi penelitian 
Tabel 1. Pengukuran data yang dibutuhkan

\begin{tabular}{llll}
\hline \multicolumn{1}{c}{ Parameter } & \multicolumn{1}{c}{ Satuan } & \multicolumn{1}{c}{ Alat } & \multicolumn{1}{c}{ Lokasi Analisis } \\
\hline A. Fisika & & & \\
Suhu & ${ }^{\circ} \mathrm{C}$ & Termometer & In situ \\
Salinitas & $\%$ Mo & Refraktometer & In situ \\
Kecerahan & Meter & Secchi Disk & In situ \\
Kedalaman & Meter & Echosounder & In situ \\
B. Kimia & & & \\
pH & - & pH meter & In situ \\
Nitrat & $\mathrm{mg} / 1$ & Spektrofotometer & Ex situ \\
Ammonia & $\mathrm{mg} / 1$ & Spektrofotometer & Ex situ \\
Fosfat & $\mathrm{mg} / 1$ & Spektrofotometer & Ex situ \\
DO & $\mathrm{mg} / 1$ & DO meter & In Situ \\
Klorofil-a & $\mu \mathrm{g} / 1$ & Spektrofotometer & Ex situ \\
\hline
\end{tabular}
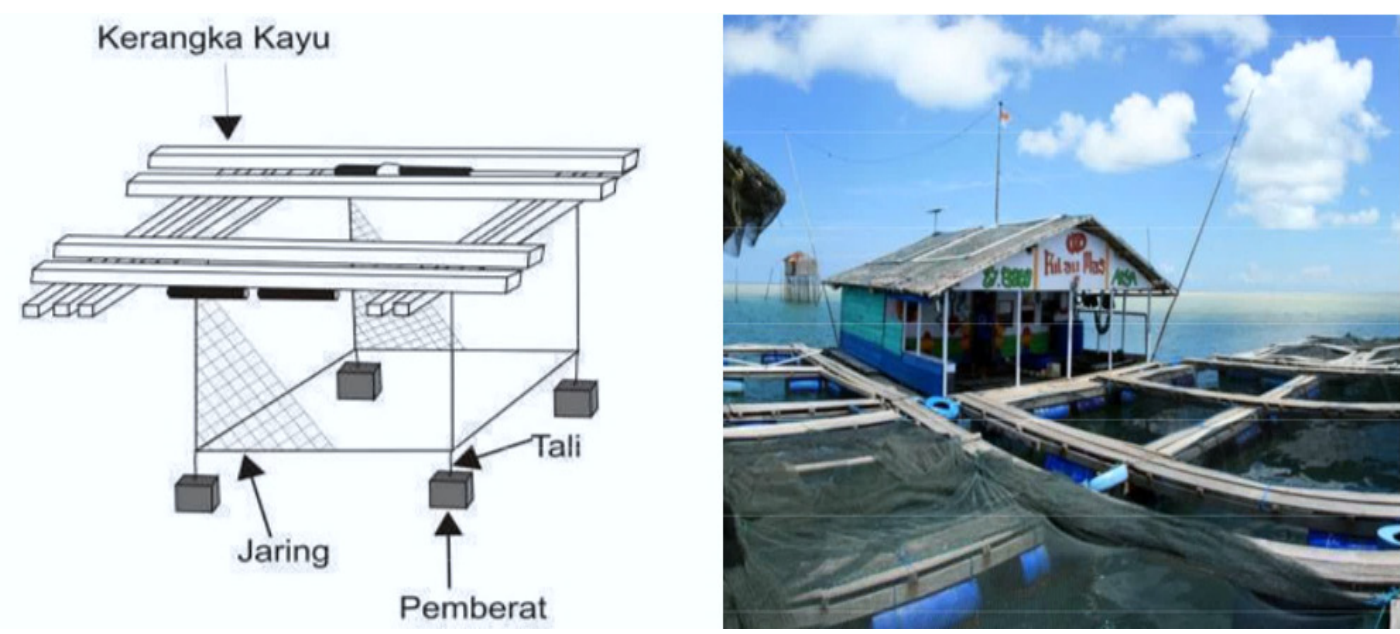

Gambar 2. Ilustrasi keramba jaring apung (Sumber: WWF-Indonesia 2011)

\section{Analisis Pendugaan Kuantitatif Limbah dari Budidaya Ikan (Internal Loading)}

Jumlah limbah yang masuk ke perairan dari kegiatan budidaya ikan kerapu diduga dari feses ikan dan dari sisa pakan yang tidak termakan. Tabel 2 merupakan pendugaan limbah dari internal loading mengacu pada Akbar et al. 2012 dan Noor (2009) in Bramana (2015).

Estimasi total bahan organik yang masuk ke perairan dihitung menggunakan metode yang dikemukakan oleh Iwama (1991) dengan mengacu pada total pakan yang tidak dikonsumsi serta jumlah feses ikan kerapu, dengan persamaan:

$$
O=T U+T F W
$$

Keterangan:

O : Total output partikel bahan organik

$T U$ : Total pakan yang tidak dimakan

TFW : Total limbah feses diperoleh dengan persamaan:

$$
T U=T F+U W
$$

Keterangan:

TF : Total pakan yang diberikan

UW : Persentase pakan yang tidak dimakan (rasio total pakan yang dimakan terhadap total pakan yang diberikan)

TFW : Total limbah feses, dihitung dengan persamaan:

$$
T F W=F \times T E
$$


Keterangan:

E : Persentase feses (rasio total feses terhadap total pakan yang dimakan)

TE : Total pakan yang dimakan, diperoleh menggunakan persamaan

$$
T E=T F-T U
$$

Keterangan:

TF : Total pakan yang diberikan

$T U$ : Total pakan yang tidak dimakan

Pendugaan dalam kuantifikasi dari total limbah $\mathrm{N}$ berdasarkan data kandungan $\mathrm{N}$ dalam pakan dan dalam karkas ikan kerapu (Barg 1992). Pendugaan total N mengacu pada metode Barg (1992), menghitung Loading $N$ dengan persamaan:

$$
K g N=(A \times C d n)-(B \times C f n)
$$

Keterangan:

A : Bobot basah pakan yang digunakan (kg)

$B \quad$ : Bobot basah kerapu yang diproduksi (kg)

$\mathrm{Cd} \quad$ : Kandungan nitrogen (Cdn) pada pakan diekspresikan sebagai \% dari bobot basah

Cf : Kandungan nitrogen (Cfn) dari karkas ikan diekspresikan sebagai $\%$ dari bobot basah

Tabel 2. Nilai parameter penentuan beban limbah budidaya ikan kerapu dalam keramba jaring apung

\begin{tabular}{llcc}
\hline No & \multicolumn{1}{c}{ Parameter yang di analisis } & Nilai & Satuan \\
\hline 1 & Ratio Konversi Pakan (FCR) & $6,0^{*}$ & \\
2 & Kandungan N dalam pakan & 12,6 & $\%$ \\
3 & Kandungan N dalam pakan yang habis & 82 & $\%$ \\
4 & Kandungan N dalam pakan yang terbuang & 18 & $\%$ \\
5 & Kandungan dalam kecernaan pakan & 81 & $\%$ \\
6 & Kandungan N dalam feses & 19 & $\%$ \\
7 & Kandungan N dalam daging & 26,1 & $\%$ \\
8 & Kandungan N dalam ekskresi & 73,9 & $\%$ \\
\hline
\end{tabular}

Sumber: *Akbar et al. (2012) dan Noor (2009) in Bramana (2015)

\section{Analisis Pendugaan Kuantitatif Limbah Berasal dari Daratan (Eksternal Loading)}

Pendugaan beban limbah yang berasal dari daratan atau dari kegiatan masyarakat mengacu pada metode yang dikembangkan oleh Rachmansyah (2004). Beban limbah yang berasal dari pemukiman diperoleh dari data penghitungan secara langsung di lokasi pengamatan yang mengacu pada data sekunder (Tabel 3). Pendugaan total nitrogen (TN) dari limbah antropogenik dapat dihiting dengan mengkalikan antara tingkat aktivitas kegiatan (jumlah penduduk) dengan koefisien limbah $(\mathrm{kg} \mathrm{N})$, dengan persamaan:

Total $N=$ Level aktivitas (jumlah penduduk) $x$ Koefisien limbah $(\mathrm{kg} \mathrm{N})$

Tabel 3. Jenis aktifitas dan koefisien limbah pemukiman

\begin{tabular}{lc}
\hline \multicolumn{1}{c}{ Jenis Aktivitas Pemukiman } & Koefisien Limbah \\
\hline Limbah Padat & $1,86 \mathrm{~kg} \mathrm{~N} / \mathrm{org} / \mathrm{th}^{1}$ \\
Sampah & $4 \mathrm{~kg} \mathrm{~N} / \mathrm{org} / \mathrm{th}^{2}$ \\
\hline
\end{tabular}

Sumber: 1) Sogreah (1974) in Bramana 2015; 2) Padilla et al (1997) in Rachmansyah (2004) 


\section{Pendugaan Daya Dukung Lingkungan Perairan Bagi Pengembangan KJA}

Tinggi rendahnya kadar nutrien di perairan menurut Gowen et al. 1989 in Barg (1992) ditentukan oleh beberapa faktor yaitu volume badan air, laju pembilasan dan fluktuasi pasang surut. Adapun persamaannya sebagai berikut:

$$
\mathrm{Ec}=\frac{N x F}{V}
$$

Keterangan:

Ec : Konsentrasi limbah $\mathrm{N}(\mathrm{mg} / \mathrm{l})$

$N \quad$ : Output harian dari limbah nitrogen terlarut $(\mathrm{mg} / \mathrm{l})$

$F \quad$ : Flushing time dari badan air (hari)

$V \quad$ : Volume badan air $\left(\mathrm{m}^{3}\right)$

Flushing time merupakan waktu (jumlah hari) yang diperlukan limbah berdiam (tinggal) dalam badan air sehingga lingkungan perairan menjadi bersih. Periode pasut di Teluk Awang, Kab Lombok Tengah termasuk pasut tipe ganda (semidiurnal tides) dengan bilangan Formzal 0,25. Penentuan flushing time ditentukan dengan menggunakan rumus:

$$
F=\frac{1}{D} ; D=\frac{(V h-V i)}{T x V h}
$$

Keterangan:

$\begin{array}{ll}F & : \text { Flushing time (hari) } \\ D & : \text { Laju pengenceran } \\ (V h-V i) & : \text { Volume pergantian pasang }\left(\mathrm{m}^{3}\right) \\ V h & : \text { Volume air dalam badan air } \\ & \text { saat pasang tertinggi }\left(\mathrm{m}^{3}\right) \\ V i & : \text { Volume air dalam badan air } \\ & \text { saat surut }\left(\mathrm{m}^{3}\right) \\ T & : \text { Periode pasang dalam satuan } \\ & \text { hari }\end{array}$

Perhitungan volume dilakukan pada saat kondisi perairan pasang tertinggi MHWS (Mean High Water Spring) dan pada saat kondisi perairan surut terendah MLWS (Mean Low Water Spring), data pasang surut mengacu dengan menggunakan data BIG (2015) dengan menggunakan persamaan sebagai berikut:

$$
V h=A x h_{i} \text { dan } V i=A x h_{o}
$$

Keterangan:

A : Luas perairan teluk $\left(\mathrm{m}^{2}\right)$

$h_{1}$ dan $h_{0}$ : Kedalaman perairan saat

pasang tertinggi dan surut terendah $(\mathrm{m})$

$V h$

Vi : Volume air pada saat surut terendah $\left(\mathrm{m}^{3}\right)$

$V h-V i \quad$ : Perubahan volume karena pasang surut $\left(\mathrm{m}^{3}\right)$

\section{Beban Pencemaran}

Perhitungan selanjutnya dengan menganalisis beban pencemaran yang masuk kedalam perairan teluk. Analisis beban pencemaran yang dihasilkan dari limbah antropogenik (daratan) yang masuk ke perairan teluk. Cara perhitungan beban pencemaran berdasarkan atas pengukuran debit air dan konsentrasi limbah daratan yang masuk ke dalam perairan dengan persamaan (Mitsch \& Goesselink 1993 in Marganof 2007) adalah:

$$
B P=Q \times C
$$

Keterangan:

$$
\begin{array}{ll}
B P & : \text { Beban pencemaran }(\mathrm{kg} / \mathrm{th}) \\
Q & : \text { Volume air }\left(\mathrm{m}^{3}\right) \\
C & \text { : konsentrasi limbah } \mathrm{N}\left(\mathrm{NH}_{3}\right)(\mathrm{mg} / \mathrm{l})
\end{array}
$$

Konsentrasi limbah yang diteliti terdapat dua nilai konsentrasi yang berbeda, yaitu konsentrasi yang masuk ke perairan dengan konsentrasi yang sudah ada. Oleh karena itu untuk mengetahui total konsentrasi limbah yang masuk ke perairan, dilakukan dengan model perhitungan menurut Bramana (2015) sebagai berikut:

$$
\text { Q3.C3 }=\text { Q1.C1+Q2.C }
$$

Berdasarkan model perhitungan diatas, maka diperoleh nilai total konsentrasi limbah yang masuk ke perairan (C3) sebagai berikut:

$$
C 3=\frac{Q 1 \cdot C 1+Q 2 \cdot C 2}{Q 3}
$$

Keterangan:

C1 : Konsentrasi limbah yang masuk $\mathrm{NH}_{3}(\mathrm{mg} / \mathrm{l})$

C2 : Konsentrasi limbah di lokasi $\mathrm{NH}_{3}$ (mg/l)

C3 : Total nilai konsentrasi NH3 (mg/l)

Q1 : Volume air masuk $\left(\mathrm{m}^{3}\right)$

Q2 : Volume air yang ada di lokasi $\left(\mathrm{m}^{3}\right)$

Q3 : Volume air total $\left(\mathrm{m}^{3}\right)$ 


\section{Daya Tampung}

Daya tampung yaitu batas kemampuan sumber daya air untuk menerima masukkan beban pencemaran yang tidak melebihi batas syarat kualitas air untuk berbagai pemanfaatannya dan memenuhi baku mutu air (Machbub 2010) dengan rumus:

\section{Daya Tampung = Baku Mutu $\mathrm{NH}_{3}-\mathrm{N}-$ Total Konsentrasi limbah $\left(\mathrm{NH}_{3}-\mathrm{N}\right)$}

$$
\text { Jumlah Unit }=\frac{\text { Daya tampung }}{E c}
$$

\section{HASIL DAN PEMBAHASAN}

\section{Keadaan Umum Lokasi Penelitian}

Secara adminstrasi Teluk Awang dan Teluk Bumbang merupakan bagian Desa Mertak Kecamatan Pujut dengan perairan yang berarus relatif kecil sehingga mendukung kegiatan budidaya. Luas perairan Teluk Awang adalah 258,33 ha, sedangkan luas perairan Teluk Bumbang adalah 940 ha. Tingkat kedalaman pada perairan Teluk Awang dan Teluk Bumbang mempengaruhi kehidupan organisme budidaya laut terutama menggunakan sistem keramba jaring apung. Kedalaman suatu perairan merupakan faktor yang diperlukan untuk kegiatan budidaya terhadap organisme yang membutuhkan kedalaman rendah sampai cukup dalam. Nilai rata-rata kedalaman di perairan Teluk Awang berkisar antara 1,5 m sampai 9,6 $\mathrm{m}$ dan Teluk Bumbang berkisar antara 3,5 m sampai 15,1 m. Menurut penelitian Djokosetiyanto et al. (2017) kedalaman budidaya ikan dalam KJA berkisar antara 2,28 m sampai 18,58 m. Kecerahan merupakan suatu kondisi yang menunjukkan kemampuan cahaya untuk menembus lapisan air pada kedalaman tertentu. Pada perairan alami, kecerahan sangat penting karena erat kaitannya dengan aktifitas fotosintesis. Kecerahan merupakan faktor penting bagi proses fotosintesa dan produksi primer dalam suatu perairan. Hasil perhitungan kecerahan rata-rata perairan di Teluk Awang berkisar antara 1,3 m sampai $9 \mathrm{~m}$ sedangkan Teluk Bumbang berkisar antara 3,2 m smpai 14 m. Penelitian Bramana (2015) kecerahan perairan untuk KJA berkisar antara 5,6 m sampai 9,4 m Kecerahan perairan relatif tidak berfluktuasi tinggi sepanjang waktu namun memiliki kecenderungan meningkat selama waktu pengamatan.

Suhu merupakan salah satu faktor penting dan pengaruh bagi perkembangan dan kehidupan seluruh biota laut. Peningkatan suhu perairan sebesar $10^{\circ} \mathrm{C}$ dapat menyebabkan terjadinya peningkatan konsumsi oksigen oleh organisme akuatik sebanyak dua sampai tiga kali lipat. Ratarata suhu di perairan Teluk Awang berkisar antara $29,65^{\circ} \mathrm{C}$ sampai $30,7^{\circ} \mathrm{C}$, sedangkan Teluk Bumbang berkisar antara $29,75{ }^{\circ} \mathrm{C}$ sampai $31,2{ }^{\circ} \mathrm{C}$. Penelitian Affan (2011) di perairan Pantai Timur Kab. Bangka Tengah kisaran suhu perairan untuk budidaya ikan dalam KJA berkisar $27^{\circ} \mathrm{C}$ sampai $32{ }^{\circ} \mathrm{C}$ dan penelitian Bramana (2015) kisaran suhu untuk budidaya ikan kerapu dalam KJA $29{ }^{\circ} \mathrm{C}$ sampai $31{ }^{\circ} \mathrm{C}$. Salinitas merupakan parameter yang krusial untuk kultur dari setiap komoditas organisme laut. Salinitas memiliki peranan penting yaitu untuk meningkatkan kelangsungan hidup dan metabolisme ikan (Hartami 2008). Ratarata nilai salinitas di perairan Teluk Awang berkisar antara 32,06\% sampai 32,97\%o, sedangkan Teluk Bumbang berkisar antara 32,59\% sampai 33,24\% . Menurut penelitian Harianto dan Efendi (2017) kisaran salinitas untuk budidaya ikan dalam KJA 33,5\% sampai 33,6\%o.

$\mathrm{pH}$ atau derajat keasaman adalah suatu pernyataan dari konsentrasi ion hidrogen dalam air. Rata-rata nilai $\mathrm{pH}$ di perairan Teluk Awang berkisar antara 8,51 sampai 8,67 sedangkan Teluk Bumbang berkisar antara 8,61 sampai 8,85. Penelitian Harianto dan Efendi (2017) nilai pH berkisar antara 7,89 sampai 8,35. Oksigen terlarut adalah konsentrasi gas oksigen yang terlarut dalam air dan merupakan salah satu faktor yang penting dalam kehidupan organisme untuk respirasi. Hasil pengukuran oksigen terlarut di perairan Teluk Awang berkisar antara 5,51 mg/1 sampai 6,65 mg/1, sedangkan Teluk Bumbang berkisar antara $5,81 \mathrm{mg} / 1$ sampai $8,89 \mathrm{mg} / 1$. Penelitian Yulianto et al. (2015), oksigen terlarut untuk KJA berkisar antara 5,26 sampai 6,65 mg/1 dan penelitian Purnawan et al. (2015) kisaran oksigen terlarut untuk budidaya ikan dalam KJA 5,1 mg/1 sampai 5,8 mg/1. Ammonia merupakan senyawa nitrogen dalam air laut terdapat dalam bentuk utama yang berada dalam keseimbangan sebagai ammonia, nitrit dan nitrat. Keseimbangan ini dipengaruhi oleh kandungan oksigen dalam air. Kadar ammonia di perairan Teluk 
Awang berkisar antara $0,001 \mathrm{mg} / 1$ sampai 0,037 mg/l, sedangkan Teluk Bumbang berkisar antara $0,001 \mathrm{mg} / 1$ sampai 0,018 mg/l. Penelitian Noor (2009) kadar ammonia untuk budidaya ikan dalam KJA berkisar $0,031 \mathrm{mg} / 1$ sampai $0,149 \mathrm{mg} / 1$.

Nitrat merupakan bentuk kandungan nitrogen utama pada perairan alami. Kondisi keberadaan nitrat di perairan berkaitan dengan kondisi oksigen yang berada di perairan, apabila kondisi oksigen berada dalam kondisi yang normal maka kondisi perairan cenderung menuju nitrat. Namun tingginya kadar nitrat juga dapat membahayakan bagi kondisi perairan. Hasil pengukuran nilai kandungan nitrat di perairan Teluk Awang berkisar antara 0,012 $\mathrm{mg} / 1$ sampai $0,675 \mathrm{mg} / 1$, sedangkan Teluk Bumbang berkisar antara 0,02 mg/1 sampai $0,901 \mathrm{mg} / 1$. Penelitian Bramana (2015) di perairan Pulau Semak Daun Kepulauan Seribu, kadar nitrat didapat berkisar antara $0,033 \mathrm{mg} / 1$ sampai 0,364 $\mathrm{mg} / 1$. Fosfat dalam bentuk larutan dikenal dengan orthofosfat dan merupakan bentuk fosfat yang digunakan oleh tumbuhan dan fitoplankton. Hasil pengamatan yang dilakukan, kadar fosfat di perairan Teluk Awang yaitu $0,03 \mathrm{mg} / 1$ sampai $0,685 \mathrm{mg} / 1$, sedangkan Teluk Bumbang yaitu $0,03 \mathrm{mg} / 1$ sampai $1,855 \mathrm{mg} / 1$. Menurut penelitian Yulius et al. (2016) kadar fosfat di Teluk Saleh berkisar antara $0,03 \mathrm{mg} / 1$ sampai $0,65 \mathrm{mg} / 1$. Kesuburan perairan, salah satu indikatornya dinyatakan dalam konsentrasi klorofil-a (Basmi 2000). Hasil pengamatan klorofil-a di Teluk Awang berkisar antara 0 sampai $1,548 \mathrm{mg} / 1$ dengan rata-rata 0,1383 $\mathrm{mg} / 1$, sedangkan Teluk Bumbang berkisar antara 0 sampai $0,1601 \mathrm{mg} / 1$ dengan rata- rata $0,0543 \mathrm{mg} / 1$. Penelitian Kangkan (2006) di Teluk kupang, kadar klorofil-a bervariasi antara $0,033 \mathrm{mg} / 1$ sampai 0,037 $\mathrm{mg} / 1$. Perbedaan nilai klorofil-a disebabkan oleh keberadaan fitoplankton, baik kelimpahannya maupun komposisi jenis terhadap pigmen yang dikandungnya.

\section{Pendugaan Limbah Berasal dari Kegiatan Budidaya (Internal Loading)}

Budidaya ikan kerapu (Epinephelus $s p$ ) memiliki kelebihan yakni dari segi protein yang tinggi, permintaan pasar domestik yang tinggi dan meningkat sehingga menuntut pembudidaya untuk terus meningkatkan usaha budidaya. Semakin tinggi jumlah permintaan ikan kerapu (Epinephelus $s p$ ), maka jumlah limbah yang dihasilkan budidaya juga meningkat, sehingga dilakukan estimasi limbah yang berasal dari budidaya KJA. Kajian dalam penelitian ini pada kegiatan budidaya ikan kerapu (Epinephelus sp) keramba jaring apung memiliki ukuran satu unit keramba dengan ukuran $4 \times 4 \times 4 \mathrm{~m}$, diasumsikan penebaran ikan pada satu unit keramba berisikan empat petakan dengan padat tebar 500 ekor/ keramba berat ikan rata-rata 450 gram/ ekor. Maka satu unit keramba diperkirakan berisi 2.000 ekor ikan. Jika diperkirakan tingkat kelangsungan hidup $80 \%$, pada saat pemanenan diperkirakan mendapat 1.600 ekor ikan. Total produksi yang dalam pemeliharaan enam bulam yaitu sebesar $720 \mathrm{~kg}$ ikan kerapu (Epinephelus sp). Acuan yang digunakan pada penelitian ini Noor (2009) in Bramana (2015) dengan estimasi pengembangan formula dari kondisi pakan yang masuk ke perairan (Tabel 4).

Tabel 4. Penghitungan pendugaan limbah $\mathrm{N}$ dari kegiatan budidaya ikan kerapu di keramba jaring apung

\begin{tabular}{llcc}
\hline No & \multicolumn{1}{c}{ Parameter yang di analisa } & Nilai & $\begin{array}{c}\text { Total (kg)/6 } \\
\text { Bulan/Unit }\end{array}$ \\
\hline 1 & Ratio Konversi Pakan (FCR) & 6,0 & 4.320 \\
2 & Kandungan N dalam pakan (\%) & 12,6 & 544,32 \\
3 & Kandungan N dalam pakan yang habis (\%) & 82 & 446,34 \\
4 & Kandungan N dalam pakan yang terbuang (\%) & 18 & 97,98 \\
5 & Kandungan dalam kecernaan pakan (\%) & 81 & 361,54 \\
6 & Kandungan N dalam feses (\%) & 19 & 84,80 \\
7 & Kandungan N dalam daging (\%) & 26,1 & 94,36 \\
8 & Kandungan N dalam ekskresi (\%) & 73,9 & 267,18 \\
\hline
\end{tabular}


Hasil penghitungan dari tabel, untuk mendapatkan jumlah ikan per unit dengan mengkalikan total produksi ikan sebesar $720 \mathrm{~kg}$ dengan nilai FCR sehingga didapat hasil $4.320 \mathrm{~kg} /$ unit. Kandungan N dalam pakan didapat mengkalikan nilai $\mathrm{N}$ dalam pakan $12,6 \%$ dengan total produksi sebesar $4.320 \mathrm{~kg}$ sehingga hasil yang didapatkan sebesar 544,32 kg. Kandungan N dalam pakan yang habis didapat dengan mengkali nilai $\mathrm{N}$ pakan yang habis sebesar $82 \%$ dengan total kandungan $\mathrm{N}$ dalam pakan $544,32 \mathrm{~kg}$ sehingga hasil yang didapatkan sebesar 446,34 kg. Kandungan N dalam pakan yang terbuang dihasilkan dengan mengkalikan kandungan $\mathrm{N}$ pakan terbuang $18 \%$ dengan $\mathrm{N}$ pakan yang habsi 544,32 $\mathrm{kg}$ sehingga didapatkan hasil 97,98 $\mathrm{kg}$. Kandungan N dalam kecernaan makanan didapat dengan mengkalikan nilai N 81\% dengan total $\mathrm{N}$ pakan yang habis sebesar 446,34 kg sehingga didapat hasil 361,54 $\mathrm{kg}$. Kandungan $\mathrm{N}$ dalam feses didapat dengan mengkalikan nilai N 19\% dengan nilai $\mathrm{N}$ pakan yang habis sebesar 446,34 kg sehingga hasil yang didapatkan sebesar $84,80 \mathrm{~kg}$. Kandungan $\mathrm{N}$ dalam daging didapat dengan mengkalikan N 26,1\% dengan nilai $\mathrm{N}$ dalam kecernaan pakan sebesar $361,54 \mathrm{~kg}$ sehingga didapat hasil 94,36 $\mathrm{kg}$. Kandungan N dalam ekskresi didapat dengan mengkalikan N 73,9\% dengan nilai N dalam kecernaan pakan sebesar $361,54 \mathrm{~kg}$ sehingga hasil yang didapat sebesar 267,18 $\mathrm{kg}$. Untuk mengetahui total loading $\mathrm{N}$ dari kegiatan budidaya keramba jaring apung dengan menghitung nilai $\mathrm{N}$ pakan sisa/ terbuang $97,98 \mathrm{~kg}$ ditambah dengan nilai $\mathrm{N}$ dalam feses $84,80 \mathrm{~kg}$ ditambah dengan nilai
N dari hasil ekskresi 267,18 kg sehingga didapat hasil sebesar 449,96 kg N.

\section{Estimasi Pendugaan Limbah dari Daratan (Eksternal Loading)}

Pendugaan beban limbah dari aktivitas masyarakat yang berada di wilayah daratan dengan mengacu pada Rachmansyah (2004), yaitu sumber dari pendugaan limbah yang dapat berasal dari daratan seperti aktivitas pemukiman, sehingga bertujuan untuk mengetahui seberapa besar kontribusi beban limbah organik (nitrogen) yang masuk ke perairan. Maka dapat diketahui hasil identifikasi dari jenis dan tingkat aktivitas serta pendugaan limbah antropogenik yang ada disekitar wilayah perairan teluk. Hasil perhitungan pendugaan (Tabel 3), menunjukkan dampak dariaktivitas masyarakatmemilikikontribusi yang cukup besar. Berdasarkan data survei KAP 2015, Teluk Awang dan Teluk Bumbang merupakan bagian wilayah Desa Mertak dengan jumlah penduduknya sebesar 8.127 orang. Berdasarkan perhitungan, pendugaan jumlah kadar total $\mathrm{N}$ yang ada di Teluk Awang dan Teluk Bumbang yaitu sebesar 47.624,22 kg/tahun. Jika diasumsikan limbah organik yang masuk ke perairan Teluk Awang dan Teluk Bumbang dari kegiatan antropogenik sebesar 30\%, maka nilai $\mathrm{N}$ sebesar 14.287,27 kg/tahun. Apabila dikonversikan berdasarkan harian, maka dalam jangka satu tahun kadar limbah dari kegiatan antropogenik yaitu sebesar $39,14 \mathrm{~kg} /$ hari (Tabel 5) dan pendugaan daya dukung pendekatan beban limbah N (NH3) (Tabel 6).

Tabel 5. Pendugaan beban limbah antropogenik perairan Teluk Awang dan Teluk Bumbang

\begin{tabular}{ccccc}
\hline $\begin{array}{c}\text { Jenis } \\
\text { Aktivitas } \\
\text { Pemukiman }\end{array}$ & $\begin{array}{c}\text { Koefisien } \\
\text { Limbah }\end{array}$ & $\begin{array}{c}\text { Sumber } \\
\text { Acuan }\end{array}$ & $\begin{array}{c}\text { Tingkatan } \\
\text { Aktivitas }\end{array}$ & $\begin{array}{c}\text { Total N } \\
\mathbf{( k g} / \text { th) }\end{array}$ \\
\hline Limbah Padat & $1.86 \mathrm{~kg} \mathrm{~N} / \mathrm{org} / \mathrm{th}$ & Sogreah 19741 & 8.127 orang $^{3}$ & $15.116,22$ \\
Sampah & $4 \mathrm{~kg} \mathrm{~N} / \mathrm{org} / \mathrm{th}$ & Padilla et al. 19972 & 32.508 \\
\hline Jumlah & & & $47.624,22$ \\
\hline
\end{tabular}

Sumber: (1) (2). Sogreah 1974 in Bramana (2015), Padilla et al. 1997 in Rachmansyah, 2004.

${ }^{(3)}$ Survei KAP (2015) 
Tabel 6. Hasil perhitungan pendugaan daya dukung perairan Teluk Awang

\begin{tabular}{lccc}
\hline \multicolumn{1}{c}{ Parameter Acuan } & $\begin{array}{c}\text { Teluk } \\
\text { Awang }\end{array}$ & $\begin{array}{c}\text { Teluk } \\
\text { Bumbang }\end{array}$ & Satuan \\
\hline Luas Perairan & 258,33 & 940 & $\mathrm{Ha}$ \\
Volume air pasang tertinggi & 4.715 .335 & 17.122 .067 & $\mathrm{~m}^{3}$ \\
Volume air pasang terendah & 1.053 .125 & 3.604 .116 & $\mathrm{~m}^{3}$ \\
Volume rata-rata perairan & 2.858 .435 & 10.338 .976 & $\mathrm{~m}^{3}$ \\
Flushing time & 0,3219 & 0,3167 & $\mathrm{hari}$ \\
Total pendugaan limbah antropogenik & 39,1432 & 39,1432 & $\mathrm{~kg} / \mathrm{hari}$ \\
Konsentrasi NH3 dari limbah N (C1) & 0,0044 & 0,0012 & $\mathrm{mg} / 1$ \\
Konsentrasi rata-rata NH3 di lokasi (C2) & 0,0081 & 0,0062 & $\mathrm{mg} / 1$ \\
Total konsentrasi (C3) & 0,0036 & 0,0027 & $\mathrm{mg} / 1$ \\
Daya tampung & 0,2964 & 0,2973 & $\mathrm{mg} / 1$ \\
Jumlah keramba yang dapat digunakan & 67 & 248 & $\mathrm{unit}$ \\
*Baku mutu NH ${ }_{3}$ & 0,3 & 0,3 & $\mathrm{mg} / 1$ \\
\hline
\end{tabular}

Ket: *(Kepmen LH No. 51, 2004)

\section{Beban Pencemaran dan Daya Tampung}

Sumber dari beban pencemaran pada penelitian ini dilihat dari kegiatan budidaya dan kegiatan antropogenik yang masuk ke perairan. Berdasarkan hasil perhitungan, nilai total konsentrasi limbah $\mathrm{N}\left(\mathrm{C}_{3}\right)$ di perairan Teluk Awang sebesar 0,0036 mg/1, sedangkan Teluk Bumbang sebesar 0,0027 mg/1, hasil ini merupakan dari selisih antara nilai baku mutu perairan dengan nilai konsentrasi $\mathrm{NH}_{3}$ dari limbah N. Kemudian untuk mengetahui seberapa banyak perairan menampung jumlah unit produksi, maka dilakukan penghitungan dengan cara membagi nilai daya tampung perairan terhadap limbah perairan Teluk Awang sebesar 0,2964 mg/l dan Teluk Bumbang sebesar 0,2973 mg/1 dengan nilai konsentrasi N (Ec). Nilai konsentrasi Ec Teluk Awang diketahui sebesar 0,0044 mg/1 dan nilai konsentrasi Ec Teluk Bumbang sebesar 0,0012 mg/1. Penentuan estimasi jumlah unit yang dapat mendukung kegiatan ikan kerapu dalam keramba jaring apung di Teluk Awang sebanyak 67 unit dan pada Teluk Bumbang sebanyak 248 unit.

\section{Estimasi Daya Dukung Perairan Berdasarkan Musim}

Hasil yang diperoleh dari data perhitungan estimasi pasang surut Teluk Awang berdasarkan musim barat dengan volume perairan rata-rata sebesar
2.780.245 $\mathrm{m}^{3}$ dengan daya tampung limbah $\mathrm{NH}_{3}$ sebanyak 0,2935 mg/1 dan jumlah produksi ikan sebanyak 55 ton. Pada musim timur volume rata-rata perairan sebesar 2.891.635 $\mathrm{m}^{3}$ dengan daya tampung limbah $\mathrm{NH}_{3}$ sebanyak 0,2959 mg/1 dan jumlah produksi ikan sebanyak 52 ton. Peritungan estimasi pasang surut Teluk Bumbang berdasarkan musim barat dengan rata-rata volume air sebesar 10.109.337 $\mathrm{m}^{3}$ dengan daya tampung limbah $\mathrm{NH}_{3}$ sebanyak 0,2968 $\mathrm{mg} / 1$ dan jumlah produksi ikan sebanyak 200 ton sedangkan pada musim timur volume air rata-rata sebesar 10.529 .898 $\mathrm{m}^{3}$ dengan daya tampung limbah NH3 sebanyak 0,2966 mg/l dan jumlah produksi ikan sebanyak 194 ton.

\section{KESIMPULAN}

Kesimpulan dari penelitian ini bahwa perairan Teluk Awang dan Teluk Bumbang mendukung kegiatan budidaya ikan kerapu (Ephinephelus sp), dengan hasil estimasi limbah antropogenik (daratan) sebesar 39,14 kg/tahun dengan ratarata konsentrasi limbah $\mathrm{NH}_{3}$ yang masuk ke perairan dari kegiatan budidaya ikan kerapu di Teluk Awang sebesar 0,0081 mg/1 dan 0,0062 mg/l. Jumlah unit KJA yang dihasilkan perairan Teluk Awang sebanyak 67 unit dan Teluk Bumbang sebanyak 248 unit. 


\section{UCAPAN TERIMA KASIH}

Terima kasih penulis ucapakan kepada Kepala Pusat Penelitian dan Pengembangan Sumberdaya Laut dan Pesisir, Balitbang KP-KKP atas kerjasama dalam penelitian ini dengan bantuan data dari Tim Pesisir P3SDLP.

\section{DAFTAR PUSTAKA}

Affan JM. 2011. Seleksi Lokasi Pengembangan Budi daya dalam Keramba jaring Apung (KJA) Berdasarkan Faktor Lingkungan dan Kualitas Air di perairan Pantai Timur kabupaten Bangka Tengah. J Sains MIPA. 17(3):99-106. ISSN 19781873.

Akbar S, Marsoedi, Soemarno, Kusnendar E. 2012. Pengaruh Pemberian Pakan yang Berbeda Terhadap Pertumbuhan Ikan Kerapu Macan (Ephinephelus fuscoguttatus) pada Fase Pendederan di Keramba Jaring Apung (KJA). J Teknol Pangan. 1(2):93-101.

Anggoro S. 2004. Pengelolaan Kawasan Konservasi Laut Daerah, MSDP.

Semarang (ID): Universitas Diponegoro.

Barg UC. 1992. Guildelines of the promotion of environmental management of coastal aquaculture development. FAO Fisheries Technical paper 328. FAO, Rome (IT). 122 pages.

Basmi J. 2000. Planktonologi: Plankton Sebagai Bioindikator Kualitas Perairan. Fakultas Perikanan dan Ilmu Kelautan. Bogor (ID): Institut Pertanian Bogor.

[BIG] Badan Informasi Geospasial. 2015. Pusat Jaring Kontrol Geodesi dan Geodinamika. Bogor (ID). tide.big. go.id/pasut/. Diakses 10/7/2017/ 08.45 Wib.

Bramana A. 2015. Analisis Keberlanjutan Usaha Keramba jaring Apung dengan Pendekatan Daya Dukung Lingkungan dan Sosial Ekonomi. Studi Kasus: Kelompok Sea farming Perairan Pulau Semak Daun Kepulauan Seribu DKI Jakarta. [Tesis]. Bogor (ID): Institut Pertanian Bogor.

Djokosetiyanto D, Nawati HF, Machfud, Fachrudin A. 2017. Water Quality Study for Grouper Mariculture in
Divur Bay Dullah Island, Tual City. $J$ Omni-Akuat. 13(1):117-123.

Harianto E, Efendi I. 2017. Analisis Fisika Kimia Perairan Untuk Pemilihan Lokasi Budi daya Ikan Kerapu (Serranidae) di Teluk Saleh Kabupaten Sumbawa, Nusa Tenggara Barat Dengan Metode Storet dan Analisis Multivariat. $J$ Akuakul Sungai dan Danau. 2(1):25-42.

Hartami P. 2008. Analisis wilayah perairan Teluk Pelabuhan Ratu untuk kawasan budi daya perikanan sistem keramba jaring apung [Tesis]. Bogor (ID): Institut Pertanian Bogor.

Iwama GK. 1991. Interaction Between Aquacukture and the Environment. Critical Reviews in Environmental Control. 21(2):177-216.

Kangkan AL. 2006. Studi penentuan lokasi untuk pengembangan budi daya laut berdasarkan parameter fisika, kimia, biologi di Teluk Kupang, Nusa Tenggara Timur. [Tesis]. Semarang (ID): Universitas Diponegoro.

Kementerian Lingkungan Hidup. 2004. Salinan Surat Keputusan Menteri Lingkungan Hidup Nomor 51 tahun 2004 tentang Baku Mutu Air Laut untuk Biota Laut. Jakarta (ID).

Machbub B. 2010. Model Perhitungan Daya Tampung Beban Pencemaran Air Danau dan Waduk. J Sumber daya Air. 6(2): 103-204. ISSN 1907-0276.

Marganof, Darusman LK, Riani E, Pramudya B. 2007. Analisis Beban Pencemaran, Kapasitas Asimilasi dan Tingkat Pencemaran dalam Upaya Pengendalian Pencemaran Perairan Danau Maninjau. Jurnal Perikanan dan Kelautan. 12(1):8-14. ISSN 1213-2411.

Noor A. 2009. Model Pengelolaan Kualitas Lingkungan Berbasis Daya Dukung (Carrying Capacity) Perairan Teluk Bagi Pengembangan Budidaya Keramba Jaring Apung Ikan Kerapu (Studi Kasus Di Teluk Tamiang, Kabupaten Kotabaru, Propinsi Kalimantan Selatan). [Disertasi]. Bogor (ID): Institut Pertanian Bogor.

Purnawan S, Zaki M, Asnawi TM, Setiawan I. 2015. Studi Penentuan Lokasi Budi daya Kerapu Menggunakan Keramba Jaring Apung di Perairan Timur Simeuleu. Depik. 4(1):4048. http://dx.doi.org/10.13170/ depik.1.1.2365.

Rachmansyah. 2004. Analisis Daya 
Dukung Lingkungan Perairan Teluk Awarange Kabupaten Barru Sulawesi Selatan Bagi Pengembangan Budi daya Bandeng dalam Keramba Jaring Apung. [Disertasi]. Bogor (ID): Institut Pertanian Bogor

Ramdhan M, Salim HL, Yulius, Arifin T, Fajar YP. 2014. Penetuan Teluk Berdasarkan Hukum Laut Internasional, Studi Kasus: Teluk Ekas Pulau Lombok. J Ilmiah Geomat. 20(2):159-164.

Sachoemar I, Suhendar. 2006. Analisis Daya Dukung Lingkungan Perairan Marikultur Batam ESTET (BME) Batam. Peneliti Kelautan. Badan Pengkajian dan Penerapan Teknologi. Hidrosfer. 1(2):52-60. ISSN 17041043.

[SNI] Standar Nasional Indonesia. 2006. Keramba Jaring Apung (KJA) kayu untuk Pembesaran Ikan Kerapu di Laut. Badan Standar Nasional Indonesia. SNI 7222.1. 1-7 hal.

Survei KAP (Knowledge, Attitude, Practices). 2015. Pengelolaan Pengetahuan Pembangunan Sumber daya Pesisir Rendah Emisi di NTB dan NTT.
[Laporan]. 278 hal

Tarunamulia, Hasnawi, Suhaimi RA, Mustafa A, Paena M. 2015. Perspektif Pengembangan Perikanan Budi daya Berdasarkan Karakteristik Pantai di Teluk Gerupuk dan Teluk Bumbang Kabupaten Lombok Tengah Provinsi Nusa Tenggara Barat. $J$ Riset Akuakul. 10(1):117-126.

[WWF-Indonesia] World Wide Fund for Nature. 2011. Better Management Practices. Seri Panduan Perikanan Skala Kecil Budi daya Ikan Kerapu Sistem Keramba Jaring Apung \& Tancap. Versi 1. 18 hal.

Yulianto H, Atiastari N, Damai AA. 2015. Analisis Daya Dukung Perairan Puhawng untuk Kegiatan Budi daya Keramba Jaring Apung. JIPSP. $3(1): 260-264$.

Yulius, Ardiansyah, Ramdhan M, Heriati A, Salim HL, Purbani D, Amri SN, Arifin T. 2016. Kesesuaian Kawasan Budi daya Rumput Laut di Teluk Saleh, Kabupaten Sumbawa, Nusa Tenggara Barat. Segara. 12(1):1119. http://dx.doi:10.15578/segara. v12i1.66. 